\title{
Biomarkers Reflecting The Destruction Of The Blood-Brain Barrier Are Valuable In Predicting The Risk Of Lymphomas With Central Nervous System Involvement
}

This article was published in the following Dove Press journal: OncoTargets and Therapy

\begin{abstract}
Wenjun $\mathrm{Yu}^{\mathrm{l}, *}$
Mengya $\mathrm{Si}^{2, *}$

$\mathrm{Li} \mathrm{Li}^{3, *}$

Ping $\mathrm{He}^{4}$

Zhiqiang Fan (iD) ${ }^{4}$

Qiaoxin Zhang ${ }^{2}$

Xiaoyang Jiao iD ${ }^{4}$

'Department of Hematology, The Second Affiliated Hospital of Shantou University Medical College, Shantou, Guangdong 5I504I, People's Republic of China; ${ }^{2}$ Clinical Laboratory, The First Affiliated Hospital of Shantou University Medical College, Shantou, Guangdong 5I504I, People's Republic of China; ${ }^{3}$ Obstetrics Department, The First Affiliated Hospital of Shantou University Medical College, Shantou, Guangdong 5I504I, People's Republic of China; ${ }^{4}$ Department of Cell Biology and Genetics, Shantou University Medical College, Shantou, Guangdong,

People's Republic of China
\end{abstract}

*These authors contributed equally to this work
Correspondence: Xiaoyang Jiao

Department of Cell Biology and Genetics, Shantou University Medical College, 22

Xinling Road, Guangdong 5I504I,

People's Republic of China

Email xyjiao@stu.edu.cn
Objective: We aimed to identify the biomarkers in cerebrospinal fluid (CSF) that facilitate the diagnosis of lymphomas with central nervous system (CNS) involvement.

Methods: Four cases of non-Hodgkin's lymphoma (NHL) patients with/without CNS involvement were enrolled respectively, and non-CNS tumor patients $(n=3)$ were selected to be the controls. Lab biomarkers, cytokines, and tight junction proteins (TJs) in CSF and serum were measured.

Results: When comparing the CNS to non-CNS group, cytokine including MMP-9 (15.24 vs $0.36 \mathrm{ng} / \mathrm{mL}$ ), CCL-2 (1922.04 vs $490.68 \mathrm{pg} / \mathrm{mL}$ ), and sVCAM-1 (61.36 vs $9.00 \mathrm{pg} / \mathrm{mL}$ ), TJs including OCLN (6.68 vs $2.59 \mathrm{pg} / \mathrm{mL}$ ), and ZO-1 (710.04 vs $182.98 \mathrm{pg} / \mathrm{mL}$ ) in CSF were significantly higher in lymphomas patients with CNS involvement than those without CNS involvement. However, serum biomarkers were not significantly elevated. Contrary to the major findings, all conventional biomarkers and MRI results showed no significant change. Conclusion: CSF biomarkers affecting BBB disruption are valuable in mirroring the risk of lymphoma CNS metastasis. Further study with a larger sample size is needed to verify these biomarkers in predicting lymphoma CNS involvement.

Keywords: lymphoma, CNS metastasis, cytokines, tight junction protein

\section{Introduction}

CNS involvement is a fatal complication for non-Hodgkin lymphoma (NHL), ${ }^{1}$ which incidence may arrive up to $30 \%$ for highly-aggressive lymphomas if there is no promptly CNS prophylaxis. ${ }^{2}$ The risk of CNS relapse can be reduced with high-dose methotrexate containing prophylactic chemotherapy, ${ }^{3}$ however, highdose methotrexate is a resource-demanding therapy with considerable toxicity, it should be limited to patients with a high risk of CNS recurrence. ${ }^{4}$ Radiation therapy, although effective, often associates unacceptable late adverse effects (i.e., secondary neoplasm, endocrinopathy, neurocognitive dysfunction, and neurotoxicity, etc.). ${ }^{2}$ Presently, there is no consensus regarding the best type of prophylaxis; different therapeutic modalities have been used: systemic chemotherapy, radiation therapy, or a combination. The accurate risk evaluation of lymphoma CNS metastasis is vital for determining subsequent therapy, and the laboratory biomarkers are desperately needed to define the patients in need of CNS prophylactic treatment. ${ }^{4}$ 
Currently, the patient selection for CNS prophylaxis is carried out by clinical risk assessment, including high International Prognostic Index (IPI) score, advanced tumor stage, elevated lactate dehydrogenase (LDH), age $>60$ years and involvement of extranodal sites, etc. ${ }^{4}$ Unfortunately, high-risk patients selection based on aforementioned standards has poor specificity and sensitivity. ${ }^{5}$ It is assumed that CNS relapse in NHL is likely due to occult malignant cells that have presented in CNS but may not be able to detect when the tumor is initially diagnosed. ${ }^{5}$ Peripheral tumor cells have metastasized into the CNS and developed neurologic signs for weeks, but only $20 \%$ of patients can be found by clinical symptoms. ${ }^{4}$ Presently, the evaluating system includes imaging studies such as magnetic resonance imaging (MRI) and computed tomography (CT) scan, cytologic test, and immunophenotypic biomarkers. The subclinical CNS tumor sites may remain undetected by conventional contrast-enhanced MRI scanning behind an intact neurovascular unit or blood-cerebrospinal fluid barrier, due to contrast enhancement is related to blood-brain barrier (BBB) integrity rather than actual tumor size, ${ }^{6,7}$ Then, it is difficult to make a definitive diagnosis of lymphoma CNS metastasis. ${ }^{8}$ Based on imaging techniques, the differential diagnoses also include glioma, multiple sclerosis, acute disseminated encephalomyelitis. ${ }^{9,10}$ Some biological parameters have no significant difference in both primary and secondary CNS lymphomas. Therefore, lymphoma cells in CSF are still the golden standard in diagnosis lymphoma CNS involvement; however, it is generally accepted that CSF cytology has a low sensitivity though it has high specificity, the CSF-flow cytometry and CSF-polymerase chain reaction (PCR) found similarly low sensitivities (11-16\%). ${ }^{11}$ Nowadays, lacking diagnostic biomarkers with both high sensitivity and specificity was a major obstacle for CNS lymphomas diagnosis and treatment.

In order to improve the diagnostic efficacy, there is emerging interest in finding new biomarkers, such as circulating tumor cells (CTC), proteins, as well as microRNA and DNA. ${ }^{7,12,13}$ CNS disease typically developed within a few months before the initial clinical presentation, raising the question: whether occult CNS localization was already present at the time of diagnosis. ${ }^{14}$ The BBB and the blood-cerebrospinal- fluid barrier (BCSFB) are the effective barriers to inhibit large molecules and cells into the CNS. The previous study presumed that the malignant cells originate from extracranial sites but end up coming into the CNS due to highly selective CNS tropism, where adhesion-, migration- and ECM-related molecules play a pivotal role in CNS involvement. ${ }^{15,16}$ Successful binding of lymphoma cells to the blood vessel walls of the BBB is the essential process for lymphoma invasion of the CNS. Vascular cell adhesion molecule (VCAM) results in the formation of cell connections through interactions with integrins, which promotes the cell adhesion and diapedesis, resulting in tumor growth and angiogenesis. ${ }^{17}$ It has been suggested that soluble forms of VCAMs may play an important role in cancer metastasis, and the increased expression of soluble CAMs may be a predictor of malignant disease. ${ }^{18}$ The degradation of the extracellular matrix (ECM) of blood or lymph vessels is critical to tumor metastasis. The matrix metalloproteinases (MMPs) hydrolyze ECM components in the tissues surrounding the tumor, which facilitates the invasion of tumor cells through the basement membrane to distant organs and results in metastasis. ${ }^{19,20}$ MMP-9, secreted by tumor cells, is the main member of MMP family member that plays a critical role in the degradation of type IV collagen (a major constituent of the ECM). MMP-9 can digest TJs of the BBB, enabling tumor cells to infiltrate the brain; thus, MMP-9 activities are directly correlated with their BBB migration capability. ${ }^{21}$ Monocyte chemotactic protein 1 (MCP-1/CCL2), a chemokine secreted by fibroblasts, endothelial/epithelial cells, monocytes, and some tumor cells, plays roles in the recruitment of monocytes and macrophages into inflammatory sites and regulating their activities. CCL2 recruits blood-borne cells to the sites of brain injury by offering a specific driving stimulus. ${ }^{22}$ Increased CCL2 is correlated with CNS metastasis and may be one of the mechanisms involved in CNS leukemia. ${ }^{23}$

BBB failure is a critical event in brain tumor metastasis. ${ }^{24}$ The quantity of proteins and cells in CSF is dependent on $\mathrm{CSF} /$ blood-brain barrier integrity, biomarkers in CSF may have more diagnostic value compared with those in blood. ${ }^{25-28}$ Moreover, biomarkers in CSF can reflect not only the status of malignant cells but also the tumor microenvironment in CNS. Our previous study demonstrated that CSF biomarkers, including chemokines, cytokines, and TJs had specificity and high positive predictive value in reflecting BBB damage and the potential of leukemia CNS metastasis. ${ }^{27,28}$ Compare with leukemia, and lymphoma has its unique pathophysiologic features. Presently, no clinical study shows whether the aforementioned biomarkers have equal efficacies to lymphomas CNS, and there is sparse information elucidating the role 
of these biomarkers in lymphoma CNS metastasis. In this study, we analyzed the diagnostic efficacy of the biomarkers, which will ensure optimal treatment while avoiding unnecessary therapies. $^{29}$

\section{Methods And Patients}

The study protocol was approved by the Ethics Committee of Shantou University Medical College. This study was conducted in accordance with the Declaration of Helsinki. Written informed consent was obtained from patients or their guardian. Patients with clinically or radiologically suspected were selected. The diagnosis of lymphoma was determined according to the WHO standard, CNS metastasis based on the following criteria: the presence of any number of blasts in the CSF. The inclusion criteria also included lymphoma patients suffering from typical clinical symptoms of meningitis. Accordingly, 4 cases of lymphoma with CNS metastasis, 4 cases of lymphoma without CNS metastasis were enrolled in this study, at the same time, 3 cases of acute myeloid leukemia were included as the controls. Patients underwent a lumbar puncture before intrathecal therapy injection, and the controls underwent a lumbar puncture for diagnostic purposes. The procedures were carefully controlled to avoid blood contamination due to puncture, and samples with $\mathrm{RBC} \geq 100 / \mathrm{mm}^{3}$ was excluded. CSF and serum samples were collected, the paired samples were centrifuged $\left(1,700 \mathrm{~g}, 5 \mathrm{~min}, 4^{\circ} \mathrm{C}\right)$ immediately upon isolation, the serum or cell-free CSF supernatants were collected, and the aliquots were stored at $-80^{\circ} \mathrm{C}$ until analysis.

\section{Cytokines, Chemokines And TJs Proteins Measurement}

Cytokines and Chemokines were measured by using ELISA kits from R\&D systems. The limits of sensitivity for the CCL2, sVCAM-1, and MMP-9 assays were $0.57 \mathrm{pg} / \mathrm{mL}$, 0.17 , and $0.156 \mathrm{ng} / \mathrm{mL}$, respectively. TJs measurements were conducted by ELISA method (Cusabio, America).

All process was done according to the instruction of kits.

\section{CSF And Serum Conventional Biomarkers Analyses}

The conventional biomarkers included cytological analyses: erythrocyte count, WBC count, and lymphoma cells detection. CSF was centrifuged, and the cell pellets were used for cytological examination for the presence of tumor cells in the CSF. CSF biochemical parameters include albumin (ALB) glucose and chloride. The biochemical parameters in the serum were measured according to the same protocol.

$\mathrm{BBB}$ value: the ratio of $\mathrm{CSF} /$ serum albumin, was used to evaluate the $\mathrm{BBB}$ integrity. ${ }^{25,30}$

\section{Statistical Analyses}

Continuous variables were reported as the medians with interquartile ranges (IQR). The Kruskal-Wallis H, MannWhitney U, Wilcoxon rank, and Chi-square tests were used to evaluate differences among each group. SPSS for Windows version 13.0 was used for statistical analyses (SPSS Incorporated, Chicago, IL, USA). Values of $\mathrm{p}<0.05$ were considered to be statistically significant.

\section{Results}

General characteristics of patients with CNS involvement were summarized in Table 1. Laboratory parameters including complete blood count (CBC), electrolytes, and renal and liver function tests were unremarkable except for a patient had significant elevated LDH (768.0U/L; reference range: 135-225 U/L) and thrombocytopenia of $24.00 \times 10^{9} / \mathrm{L}$ (reference range: $100-300 \times 10^{9} / \mathrm{L}$ ). However, CSF measurements showed significant change. The cytology test showed marked lymphocytic pleocytosis (patients' WBC were: 110, 1500, 115, 3540/ul, respectively;), with many immature lymphoid cells, compatible with lymphoma CNS relapsed (Figure1). To all patients with/without CNS involvement, the CT and MRI scans of the brain were no obvious changes (Figure 2), three patients had another organ invasion.

\section{Cytokines, Chemokines And TJs Proteins Measurement}

Subgroup analysis shows that CSF cytokines, including MMP-9, CCL-2, sVCAM-1, TJs including OCLN, and ZO-1 were significantly higher in lymphoma with CNS involvement than those without CNS involvement $(\mathrm{P}<0.05)$. CSF MMP-9, CCL-2, sVCAM-1, TJs including OCLN, and ZO-1 in lymphoma patients were higher than in patients with leukemia CNS involvement. Serum cytokines and TJs were measured at the same time. The results revealed that serum cytokines in the CNS metastatic group had no significant difference compared with the non-CNS metastatic group; however, serum TJs in the CNS group was higher than that in the non-CNS group. TJs remain the same trend except for the CLDN5. BBB value in the CNS 
Table I General Characteristic Of Patients With Lymphoma CNS Metastasis Survival Time Is Calculated From 2012.1I.08 To 2015.03.19

\begin{tabular}{|c|c|c|c|c|}
\hline & Patient I & Patient 2 & Patient 3 & Patient 4 \\
\hline Age (years) & 3.00 & 19.00 & 34.00 & 14.00 \\
\hline Gender & Female & Male & Female & Male \\
\hline$W_{B C} C_{\text {Blood }}(10 E+9 / L)$ & 4.21 & 2.26 & 7.16 & 6.79 \\
\hline $\mathrm{RBC}_{\text {Blood }}(10 \mathrm{E}+12 / \mathrm{L})$ & 3.73 & 2.15 & 3.87 & 2.44 \\
\hline $\mathrm{Hb}_{\text {Blood }}(\mathrm{g} / \mathrm{L})$ & 197.00 & 66.00 & 119.00 & 78.00 \\
\hline $\mathrm{PLT}_{\text {Blood }}(10 \mathrm{E}+9 / \mathrm{L})$ & 318.00 & 24.00 & 133.00 & 183.00 \\
\hline $\mathrm{LDH}_{\text {Serun }}(\mathrm{U} / \mathrm{L})$ & 86.00 & 768.00 & 216.00 & 257.00 \\
\hline $\mathrm{AST}_{\text {Serum }}(\mathrm{U} / \mathrm{L})$ & 65.00 & 10.00 & 23.00 & 21.00 \\
\hline $\mathrm{ALT}_{\text {Serum }}(\mathrm{U} / \mathrm{L})$ & 60.00 & 14.00 & 21.00 & 40.00 \\
\hline $\mathrm{GGT}_{\text {Serum }}(\mathrm{U} / \mathrm{L})$ & 23.00 & 30.00 & 27.00 & 105.00 \\
\hline $\mathrm{ALP}_{\text {Serum }}(\mathrm{U} / \mathrm{L})$ & 160.00 & 54.00 & 68.00 & 97.00 \\
\hline $\mathrm{CHE}_{\text {Serum }}(\mathrm{U} / \mathrm{L})$ & 9.42 & 3.56 & 5.10 & 5.74 \\
\hline $\mathrm{TP}_{\text {Serum }}(\mathrm{g} / \mathrm{L})$ & 62.20 & 51.00 & 59.80 & 56.40 \\
\hline $\operatorname{ALB}_{\text {Serum }}(g / L)$ & 45.30 & 30.60 & 40.40 & 37.80 \\
\hline $\operatorname{GLB}_{\text {Serum }}(g / L)$ & 16.90 & 20.40 & 19.40 & 18.60 \\
\hline $\operatorname{Glu}_{\mathrm{CSF}}(\mathrm{mmol} / \mathrm{L})$ & 4.03 & 3.11 & 0.72 & 3.49 \\
\hline $\mathrm{Cl}_{\mathrm{CSF}}(\mathrm{mmol} / \mathrm{L})$ & 122.00 & 126.00 & 113.00 & 123.00 \\
\hline $\operatorname{ALB}_{C S F}(g / L)$ & 1.13 & 0.70 & 0.96 & 0.25 \\
\hline $\mathrm{WBC}_{\mathrm{CSF}}(10 \mathrm{E}+6 / \mathrm{L})$ & 110.00 & 1500.00 & 115.00 & 3540.00 \\
\hline BBB value & 24.94 & 22.88 & 23.76 & 26.98 \\
\hline Survival time (days) & 676 & 33 & 70 & 135 \\
\hline Blasts in CSF & Not found & Not found & Found & Found \\
\hline Organ invasion & Not detected & Detected & Detected & Detected \\
\hline
\end{tabular}

Abbreviations: CSF, cerebrospinal fluid; WBC, white blood cell; RBC, red blood cell; Hb, hemoglobin; PLT, platelet; LDH, L-lactate dehydrogenase; AST, aspertate aminotransferase; ALT, alanine aminotransferase; GGT, gamma-glut amyl transpeptidase; ALP, alkaline phosphatase; CHE, cholinesterase; TP, total protein; ALB, albumin; GLB, globulin; Glu, glucose; $\mathrm{Cl}$, chloride; $\mathrm{BBB}$ value, $\mathrm{ALB}_{\mathrm{CSF}} \times 1000 / \mathrm{ALB}_{\text {Serum }}$.

group was significantly higher than in a non-CNS group, indicating $\mathrm{BBB}$ integrity damaged in the CNS group (Tables 2 and 3).

\section{Discussion}

Nowadays, clinical trials are exploring the optimum time of CNS prophylactic treatment should be performed in order to decrease the incidence of lymphoma CNS involvement, meanwhile, minimize CNS toxicity/secondary tumor due to chemotherapy and radiotherapy. Although extensive efforts have been made, the progress is limited. The management of the lymphoma CNS involvement still
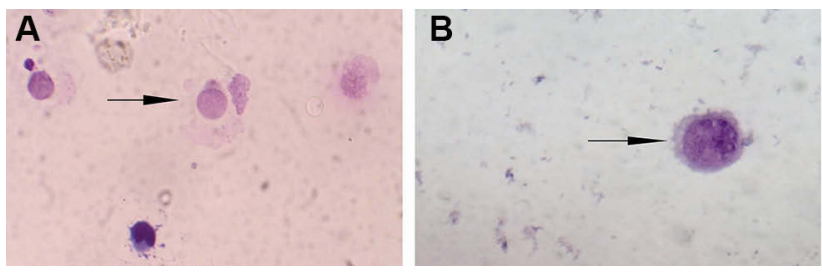

Figure I Immature cells in CSF that come from different patients (A and B) with lymphoma (black arrows), $\times 1000$. poses a major challenge in lymphoma therapy. Prophylaxis with intrathecal chemotherapy has resulted in varied outcomes. $^{31,32}$ It is currently unknown the efficacy of CNS prophylaxis at CNS relapse, and the debate on the optimal route of CNS prophylaxis (intrathecal versus systemic) is still ongoing. ${ }^{14}$ Patient's status may be the most critical factor for therapeutic efficacy, which should be accurately evaluated. In our patients with or without
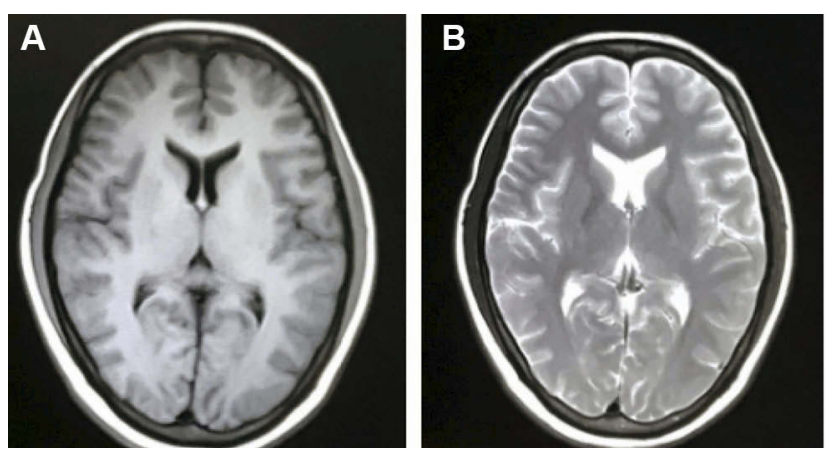

Figure 2 MRI scans (A and $\mathbf{B}$ ) of the brain revealed unremarkable changes in lymphoma patients with CNS involvement. 
Table 2 General Characteristics Of Different Groups

\begin{tabular}{|c|c|c|c|c|}
\hline & CNSL Group $(n=4)$ & Non-CNSL Group $(n=4)$ & Control $(n=3)$ & AML-Non-CNSL $(n=4)$ \\
\hline Age (years) & $16.50(8.50-26.50)$ & $\mid 4.50(8.50-\mid 5.50)$ & $19.50(12.00-27.00)$ & $17.00(16.00-29.00)$ \\
\hline $\mathrm{WBC}_{\text {Blood }}(10 \mathrm{E}+9 / \mathrm{L})$ & $5.50(3.24-6.98)$ & $4.08(2.52-6.10)$ & $8.93(5.33-11.04)$ & $5.80(4.89-6.03)$ \\
\hline $\mathrm{RBC}_{\text {Blood }}(10 \mathrm{E}+12 / \mathrm{L})$ & $3.09(2.30-3.80)$ & $3.26(2.95-4.19)$ & $3.18(1.84-4.52)$ & $3.39(2.68-3.44)$ \\
\hline $\mathrm{Hb}_{\text {Blood }}(\mathrm{g} / \mathrm{L})$ & $98.50(72.00-158.00)$ & $103.50(86.50-129.50)$ & $106.00(62.50-142.00)$ & $1 \mid 3.00(88.00-115.50)$ \\
\hline $\operatorname{PLT}_{\text {Blood }}(10 \mathrm{E}+9 / \mathrm{L})$ & $158.00(78.50-250.50)$ & $175.00(145.50-234.50)$ & $16.00(12.00-57.00)$ & $277.00(154.00-280.00)$ \\
\hline $\mathrm{LDH}_{\text {Serun }}(\mathrm{U} / \mathrm{L})$ & $236.50(151.00-512.50)$ & $221.50(179.50-231.50)$ & $292.50(239.50-448.00)$ & $148.00(\mid 36.50-156.50)$ \\
\hline $\mathrm{AST}_{\text {Serum }}(\mathrm{U} / \mathrm{L})$ & $22.00(15.50-44.00)$ & $20.00(16.50-74.00)$ & $16.50(14.50-48.00)$ & $19.00(14.00-27.50)$ \\
\hline $\mathrm{ALT}_{\text {Serum }}(\mathrm{U} / \mathrm{L})$ & $30.50(17.50-50.00)$ & $18.50(16.00-302.00)$ & $\mid 8.00(|3.00-9| .50)$ & $13.00(12.50-15.00)$ \\
\hline $\mathrm{GGT}_{\text {Serum }}(\mathrm{U} / \mathrm{L})$ & $28.50(25.00-67.50)$ & $18.00(13.00-42.00)$ & $23.50(19.50-28.50)$ & $28.00(23.00-58.00)$ \\
\hline $\operatorname{ALP}_{\text {Serum }}(\mathrm{U} / \mathrm{L})$ & $82.50(61.00-128.50)$ & $137.00(|28.50-| 78.50)$ & $133.50(93.00-174.50)$ & $120.00(\mid 17.50-133.50)$ \\
\hline $\mathrm{CHE}_{\text {Serum }}(\mathrm{U} / \mathrm{L})$ & $5.42(4.33-7.58)$ & $7.46(6.74-8.57)$ & 7.73(7.19-8.44) & $5.63(5.24-7.02)$ \\
\hline $\operatorname{TP}_{\text {Serum }}(g / L)$ & $58.10(53.70-61.00)$ & $64.95(61.95-68.50)$ & $73.60(66.05-76.65)$ & $59.50(59.30-62.35)$ \\
\hline $\operatorname{ALB}_{\text {Serum }}(g / L)$ & $39.10(34.20-42.85)$ & $41.20(38.50-44.90)$ & $41.35(37.75-48.30)$ & $35.50(35.25-35.90)$ \\
\hline $\mathrm{GLB}_{\text {Serum }}(g / L)$ & $19.00(17.75-19.90)$ & $23.10(20.75-26.30)$ & $28.60(21.35-35.30)^{*}$ & $24.00(23.40-27.10)^{* *}$ \\
\hline $\operatorname{Glu}_{\mathrm{CSF}}(\mathrm{mmol} / \mathrm{L})$ & $3.30(1.92-3.76)$ & $3.12(2.90-3.36)$ & $4.16(2.39-4.70)$ & $3.45(3.37-3.76)$ \\
\hline $\mathrm{Cl}_{\mathrm{CSF}}(\mathrm{mmol} / \mathrm{L})$ & $122.50(\mid 17.50-124.50)$ & $125.35(|2| .85-129.00)$ & $121.10(108.65-129.60)$ & $125.80(\mid 25.15-131.90)$ \\
\hline $\operatorname{ALB}_{C S F}(g / L)$ & $0.83(0.48-1.05)$ & $0.19(0.12-0.27)$ & $0.37(0.16-3.87)$ & $0.29(0.20-0.42)$ \\
\hline$W_{B C} C_{C S F}(10 E+6 / L)$ & $807.50(I 12.50-2520.00)$ & $1.50(1.00-2.00)^{* *}$ & $39.00(2.50-117.50)^{* *}$ & $2.00(1.50-3.50)^{* *}$ \\
\hline BBB value & $24.35(23.32-25.96)$ & $4.57(2.87-6.32)^{*}$ & $8.66(4.25-74.73)$ & $8.17(5.60-11.94)^{* *}$ \\
\hline
\end{tabular}

Note: $*_{p} \leq 0.05$ and $*^{*} p \leq 0.01$ when compared with lymphoma group.

Table 3 Cytokine And Tight Junction Proteins Of Different Groups

\begin{tabular}{|c|c|c|c|c|}
\hline & CNSL group $(n=4)$ & Non-CNSL(n=4) & AML-CNSL(n=3) & AML-non-CNSL(n=4) \\
\hline MMP-9 ${ }_{\mathrm{CSF}}(\mathrm{ng} / \mathrm{mL})$ & 15.24(0.49-36.46) & $0.36(0.36-0.37)^{*}$ & $0.4 I(0.39-0.50)$ & $0.37(0.37-0.38)^{* *}$ \\
\hline MMP-9 $9_{\text {Serum }}(\mathrm{ng} / \mathrm{mL})$ & $82.44(24.27-184.99)$ & $\mid 25.22(68.7|-| 69.40)$ & $79.75(18.60-538.28)$ & $127.00(73.46-793.78)^{* *}$ \\
\hline $\mathrm{CCL} 2_{\mathrm{CSF}}(\mathrm{pg} / \mathrm{mL})$ & $1922.04(|039.4|-2553.66)$ & $490.68(245.5 I-658.80)$ & $747.53(286.37-|||8| .84)^{* *}$ & $517.54(459.16-526.88)^{* *}$ \\
\hline $\mathrm{CCL} 2_{\text {Serum }}(\mathrm{pg} / \mathrm{mL})$ & $328.40(247.84-698.50)$ & $363.43(198.81-508.20)$ & $495.35(229.16-895.81)$ & $213.99(183.63-282.87)$ \\
\hline sVCAM-I ISF $(n g / m L)$ & $61.36(9.21-118.24)$ & $9.00(8.09-10.63)$ & $|2.0|(9.78-2 \mid .04)$ & $11.77(9.75-12.15)$ \\
\hline sVCAM-I Serum $(\mathrm{ng} / \mathrm{mL})$ & $1546.95(\mid 148.11-1971.14)$ & $1092.34(859.12-1361.05)$ & $2402.09(\mid 492.87-2898.95)$ & $1410.06(1090.65-1830.87)$ \\
\hline CLDN5 $5_{\mathrm{CSF}}(\mathrm{pg} / \mathrm{mL})$ & $234.92(\mid 44.77-635.82)$ & $281.06(238.08-329.27)$ & $200.22(95.65-421.64)$ & $215.42(203.54-257.04)$ \\
\hline $\mathrm{CLDN} 5_{\text {Serum }}(\mathrm{pg} / \mathrm{mL})$ & $115.75(82.18-161.60)$ & $100.93(74.44-153.18)$ & $110.61(91.90-165.48)$ & $93.23(92.03-117.20)$ \\
\hline $\mathrm{OCLN}_{\mathrm{CSF}}(\mathrm{pg} / \mathrm{mL})$ & $6.68(2.80-10.63)$ & $2.59(1.09-3.96)$ & $0.7 I(0.32-0.93)$ & $0.39(0.20-0.70)$ \\
\hline$O C L N_{\text {Serum }}(\mathrm{pg} / \mathrm{mL})$ & $7.11(3.26-16.89)$ & $6.94(4.67-9.53)$ & $15.5 \mathrm{I}(\mathrm{I} .26-22.1 \mathrm{I})$ & $7.28(5.83-10.35)$ \\
\hline ZO-I $I_{C S F}(p g / m L)$ & $710.04(590.52-777.18)$ & $182.98(\mid 74.11-191.14)^{*}$ & $208.76(\mid 43.24-394.13)$ & $122.24(\mid 10.16-167.32)^{* *}$ \\
\hline ZO-I Ierum $(\mathrm{pg} / \mathrm{mL})$ & $1549.60(\mid 121.47-1790.29)$ & $939.75(680.12-1102.58)$ & $1925.50(|7| 8.23-1976.06)$ & 1039.49(900.80-1170.52) \\
\hline
\end{tabular}

Note: $*_{p} \leq 0.05$ and $*_{p} \leq 0.01$ when compared with lymphoma group.

CNS involvement, there was no obviously different clinical manifestation between them, indicating patients could be asymptomatic in the early or late phase, and IPI score was not enough for discriminating patients with or without CNS involvement. In addition, there was no extraordinary discovery in MRI, and even patients had significantly higher lymphoma cells in CSF.

CSF cytology is still the golden standards for tumor CNS involvement; however, even when cytological examination shows no CNS involvement, approximately $10-35 \%$ of ALL patients relapse in the CNS. ${ }^{33}$ Under this circumstance, clinical risk paradigms and conventional parameters are not enough for the identification of patients with CNS metastasis. Combination of diagnostic approaches is needed to timely diagnosis and start an adequate therapeutic regimen. ${ }^{34}$ Circulating biomarkers are easily accessible, no need for the expensive instrument, and measured conveniently, which could benefit to determine risk stratification and clinical decisions, and evaluating the outcome of treatment. ${ }^{35}$

The permeability of the BBB is modulated by proteinprotein interactions of the TJs proteins. ${ }^{36}$ which are the 
first barrier that cancer cells must overcome to metastasize. $^{37}$ Though the mechanism of lymphoma CNS involvement is unclear, two mechanisms have been postulated: (1): seeding from occult reservoir lesions within the CNS (including eye and CSF), or (2): seeding from the blood and bone marrow. ${ }^{38,39}$ To secondary CNS lymphomas, the lymphoma cells need to dissociate from the primary site and enter the peripheral blood where they disseminate and infiltrate the CNS. During this process, cytokines and chemokines may play a critical role. sVCAM-1 is involved in tumor cell arrest and subsequent extravasation across the brain endothelium. ${ }^{40}$ Higher sVCAM-1 may accelerate circulating leukemic cells to target and adhere to BMVECs, making the interaction with the endothelial possible, and then enhancing the possibility of tumor cells entering the CNS. MMPs and vascular endothelial growth factor(VEGF) perturbs TJs integrity by decreasing OCLN and ZO-1 expression and causing CLDN5 and ZO-1 protein disruption. ${ }^{41,42}$ MMP-9 is critical for the breakdown of the basal membrane of the BBB. $^{43}$ In acute leukemia (AL), the degradation of TJs ZO-1, claudin-5, and occludin by MMP-2 and -9 constitutes an important mechanism in the BBB breakdown that contributes to the invasion of the CNS in AL. ${ }^{21}$ Previous studies found that MMP-9 secreted by leukemic cells degrade ZO-1, CLDN5, and OCLN, which constitute an important mechanism of the BBB breakdown. ${ }^{27}$ MMPs in the CSF may be indicative of the disruption of the BBB. ${ }^{44}$

CXCR4 signaling might participate in the initiation of lymphoma cells homing into the $\mathrm{CNS}^{4}{ }^{4} \mathrm{CXCR} 4 / \mathrm{CXCL} 12$ and CXCR5/CXCL13 axis play an important role in CNS tropism of DLBCL. ${ }^{45}$ CCL2 can be produced by neurons, astrocytes, and microglia, as well as from the choroid plexus. $^{46,47}$ There may be greater production of CCL2 in the CNS than systemically. In patients with lymphoma CNS metastasis, significantly higher levels of CCL2 was observed in CSF than in serum, high levels of CCL2 in the CSF may represent a major chemoattractant stimulus for the differential recruitment of leukocytes into the subarachnoid space. ${ }^{48}$ Compare with serum CCL2, CCL2 in $\mathrm{CSF}$ is sufficient for recruiting blood-borne cells to the sites of brain injury by offering a specific driving stimulus, and in response to leukocytes migrates across the BBB. ${ }^{49}$

The process of cancer metastasis consists of linked sequential steps, known as the metastatic cascade that includes detachment, invasion, intravasation, circulation, adhesion, extravasation, and growth in distant organs. The previous study revealed that MMP-9, CCL-2, sVCAM-1 play an important role in the metastatic cancer cascade, affecting leukemia cell CNS transferred. ${ }^{20}$ In this study, lymphoma patients with CNS involvement had significantly higher MMP-9, CCL-2, and SVCAM-1 in CSF, all of which are the key factors of metastatic cancer cascade; therefore, they may be closely associated with enhanced CNS tropism. MMP-9 facilitate the invasion of lymphoma cells through BBB by hydrolyzing ECM components in the tissues, digest TJs of the BBB. ${ }^{19,50}$ sVCAM-1 overexpression was detected in patients with non-NHL and acute leukemia. $^{51}$ In this study, significantly higher MMP-9 in CSF induced higher levels of TJs (OCLN and ZO-1) in patients with CNS lymphomas, demonstrating that higher MMP-9 has a role in promoting CNS metastasis in regulating factors relating to TJs breakdown and tumor invasion. Therefore, increased MMP-9, CCL-2, and sVCAM-1 were correlated with lymphoma CNS metastasis. We further evaluated the diagnostic efficacy of MMP-9, CCL-2, and sVCAM-1 and TJs. Our results showed that patients without CNS involvement had quite lower levels of MMP-9, CCL-2, and SVCAM-1 and TJs in $\mathrm{CSF}$, rather than in serum, indicating that CSF biomarkers had higher specificity than serum biomarkers in predicting lymphoma CNS metastasis. Considering all factors (also include age, biochemical parameters including LDH, CSF albumin, and cytology), CSF MMP-9, CCL-2, sVCAM-1, and TJs were the most significant prognostic factors for predicting lymphomas CNS metastasis, which had more valuable in mirroring the CNS status. If further verified, these biomarkers might become useful in predicting lymphoma CNS involvement.

The main limitation of our study is the small sample size; a longer prospective evaluation of a larger number of patients is necessary to confirm the clinical significance of these CSF biomarkers. In clinical routine, some patients with large, space-occupying brain tumors are not amenable for a CSF analysis due to the risk of hernia ion. ${ }^{52}$ then, we could not find suitable controls to compare these cytokines between lymphomas and solid tumors in CNS. Controversies still exist regarding the diagnostic procedure (biopsy or craniotomy), treatment strategies (methotrexate/chemotherapy/target therapy regimen, radiation therapy [RT], immunotherapy, stem cell therapy), and prognostic factors among published results. ${ }^{53}$ Although we found that CSF biomarkers are valuable in predicting lymphomas CNS involvement, validation studies with a broad patient spectrum are crucial to identify relevant cutoff values and to assess the respective diagnostic potentials of reliable biomarkers. ${ }^{52}$ 


\section{Abbreviations}

ALB, Albumin; ALL, Acute lymphoblastic leukemia; ALP, Alkaline phosphatase; ALT, Alanine aminotransferase; AML, Acute myeloid leukemia; AST, Aspertate aminotransferase; BBB, Blood-brain- barrier; BCSFB, Blood-cerebrospinal- fluid barrier; $\mathrm{CBC}$, Complete blood count; CCL-2, Chemokine ligand 2; CHE, Cholinesterase; CNS, Central nervous system; CLDN5, Claudin 5; CT, Computed tomography; CTC, Circulating tumor cell; CSF, Cerebrospinal fluid; CXCR4, C-X-C chemokine receptor type 4; CXCL12, Chemokine (C-X-C motif) ligand 12; CXCR5,C-X-C chemokine receptor type 5; CXCL13, Chemokine (C-X-C motif) ligand 13; DLBCL, Diffuse large B cell lymphoma; Hb, Hemoglobin; IPI, International Prognostic Index; GGT, Gamma-glut amyl transpeptidase; GLB, Globulin; GLU, Glucose; LDH, Lactate dehydrogenase; MMP, Matrix metalloprotein; MRI, Magnetic resonance imaging; NHL, Non- Hodgkin lymphoma; OCLN, Occludin; PCNSL, Primary central nervous system lymphoma; PCR, Polymerase chain reaction; PLT, Platelet; RBC, Red blood cell; RT, Radiation therapy; sVCAM-1, Soluble vascular cell adhesion molecule-1; VEGF, Vascular endothelial growth factor; TJs, Tight junction proteins; TP, Total protein; WBC, White blood cell; ZO-1, Zonula occludens-1.

\section{Disclosure}

The authors report no conflicts of interest in this work.

\section{References}

1. Hochberg FH, Baehring JM, Hochberg EP. Primary CNS lymphoma. Nat Clin Pract Neurol. 2007;3(1):24-35. doi:10.1038/ncpneuro0395

2. Garcia-Recio M, Cladera A, Bento L, et al. Analysis of the role of intrathecal liposomal cytarabine in the prophylaxis and treatment of central nervous system lymphomatosis: the Balearic Lymphoma Group experience. PLoS One. 2017;12(6):e0179595. doi:10.1371/journal.pone.0179595

3. Holte H, Leppa S, Bjorkholm M, et al. Dose-densified chemoimmunotherapy followed by systemic central nervous system prophylaxis for younger high-risk diffuse large B-cell/follicular grade 3 lymphoma patients: results of a phase II Nordic Lymphoma Group study. Ann Oncol. 2013;24(5):1385-1392. doi:10.1093/annonc/mds621

4. Lemma SA, Kuusisto M, Haapasaari KM, et al. Integrin alpha 10, CD44, PTEN, cadherin-11 and lactoferrin expressions are potential biomarkers for selecting patients in need of central nervous system prophylaxis in diffuse large B-cell lymphoma. Carcinogenesis. 2017;38(8):812-820. doi:10.1093/carcin/bgx061

5. Siegal T, Goldschmidt N. CNS prophylaxis in diffuse large B-cell lymphoma: if, when, how, and for whom? Blood Rev. 2012;26(3):97-106.

6. Ambady P, Fu R, Netto JP, et al. Patterns of relapse in primary central nervous system lymphoma: inferences regarding the role of the neurovascular unit and monoclonal antibodies in treating occult CNS disease. Fluids Barriers CNS. 2017;14(1):16.

7. Ambady P, Bettegowda C, Holdhoff M. Emerging methods for disease monitoring in malignant gliomas. CNS Oncol. 2013;2(6):511-522. doi:10.2217/cns. 13.44
8. Marinelli L, Tenore GC, Novellino E. Probiotic species in the modulation of the anticancer immune response. Semin Cancer Biol. 2017;46:182-190. doi:10.1016/j.semcancer.2017.08.007

9. Toh CH, Wei K-C, Chang C-N, Ng S-H, Wong H-F. Differentiation of primary central nervous system lymphomas and glioblastomas: comparisons of diagnostic performance of dynamic susceptibility contrast-enhanced perfusion MR imaging without and with contrastleakage correction. AJNR Am J Neuroradiol. 2013;34(6):1145-1149. doi:10.3174/ajnr.A3383

10. Maza S, Buchert R, Brenner W, et al. Brain and whole-body FDGPET in diagnosis, treatment monitoring, and long-term follow-up of primary CNS lymphoma. Radiol Oncol. 2013;47(2):103-110. doi:10. 2478/raon-2013-0016

11. Fischer L, Martus $P$, Weller M, et al. Meningeal dissemination in primary CNS lymphoma: a prospective evaluation of 282 patients. Neurology. 2008;71(14):1102-1108. doi:10.1212/01.wnl.0000326958.52546.f5

12. Baraniskin A, Kuhnhenn J, Schlegel U, et al. Identification of microRNAs in the cerebrospinal fluid as a marker for primary diffuse large B-cell lymphoma of the central nervous system. Blood. 2011;117(11):3140-3146. doi:10.1182/blood-2010-09-308684

13. Wang Y, Springer S, Zhang M, et al. Detection of tumor-derived DNA in cerebrospinal fluid of patients with primary tumors of the brain and spinal cord. Proc Natl Acad Sci U S A. 2015;112(31):97049709. doi:10.1073/pnas. 1511694112

14. van Rooijen CR, Scholtens AM, de Jong CN, Saraber CE. van de Donk N: primary cardiac lymphoma with central nervous system relapse. Clin Case Rep. 2017;5(9):1454-1458. doi:10.1002/ccr3.1094

15. Jiang L, Marlow LA, Cooper SJ, et al. Selective central nervous system tropism of primary central nervous system lymphoma. Int $J$ Clin Exp Pathol. 2010;3(8):763-767.

16. Tun HW, Personett D, Baskerville KA, et al. Pathway analysis of primary central nervous system lymphoma. Blood. 2008;111 (6):3200-3210. doi:10.1182/blood-2007-10-119099

17. Alexiou D, Karayiannakis AJ, Syrigos KN, et al. Serum levels of E-selectin, ICAM-1 and VCAM-1 in colorectal cancer patients: correlations with clinicopathological features, patient survival, and tumor surgery. Eur J Cancer. 2001;37(18):2392-2397. doi:10.1016/ s0959-8049(01)00318-5

18. Hatzistilianou M, Athanassiadou F, Agguridaki C, Catriu D. Circulating soluble adhesion molecule levels in children with acute lymphoblastic leukemia. Eur J Pediatr. 1997;156(7):537-540. doi:10. 1007/s004310050657

19. Valastyan S, Weinberg RA. Tumor metastasis: molecular insights and evolving paradigms. Cell. 2011;147(2):275-292. doi:10.1016/j. cell.2011.09.024

20. Yilmaz M, Christofori G, Lehembre F. Distinct mechanisms of tumor invasion and metastasis. Trends Mol Med. 2007;13(12):535-541. doi:10.1016/j.molmed.2007.10.004

21. Feng S, Cen J, Huang Y, et al. Matrix metalloproteinase-2 and -9 secreted by leukemic cells increase the permeability of blood-brain barrier by disrupting tight junction proteins. PLoS One. 2011;6(8): e20599. doi:10.1371/journal.pone.0020599

22. Schilling M, Strecker JK, Schabitz WR, Ringelstein EB, Kiefer R. Effects of monocyte chemoattractant protein 1 on blood-borne cell recruitment after transient focal cerebral ischemia in mice. Neuroscience. 2009;161 (3):806-812. doi:10.1016/j.neuroscience.2009.04.025

23. Eisenkraft A, Keidan I, Bielorai B, Keller N, Toren A, Paret G. MCP-1 in the cerebrospinal fluid of children with acute lymphoblastic leukemia. Leuk Res. 2006;30(10):1259-1261. doi:10.1016/j.leukres.2006.01.017

24. Arshad F, Wang L, Sy C, Avraham S, Avraham HK. Blood-brain barrier integrity and breast cancer metastasis to the brain. Patholog Res Int. 2010;2011:920509.

25. Tang YT, Jiang F, Guo L, Si MY, Jiao XY. Expression and significance of vascular endothelial growth factor $\mathrm{A}$ and $\mathrm{C}$ in leukemia central nervous system metastasis. Leuk Res. 2013;37(4):359-366. doi:10. 1016/j.leukres.2012.10.008 
26. Tang YT, Jiang F, Guo L, Si MY, Jiao XY. The soluble VEGF receptor 1 and 2 expression in cerebral spinal fluid as an indicator for leukemia central nervous system metastasis. J Neurooncol. 2013;112(3):329-338. doi:10.1007/s11060-013-1066-x

27. Si MY, Fan ZC, Li YZ, Chang XL, Xie QD, Jiao XY. The prognostic significance of serum and cerebrospinal fluid MMP-9, CCL2, and sVCAM-1 in leukemia CNS metastasis. J Neurooncol. 2015;122 (2):229-244. doi:10.1007/s11060-014-1707-8

28. Zhu JC, Si MY, Li YZ, et al. Circulating tight junction proteins mirror blood-brain barrier integrity in leukemia central nervous system metastasis. Hematol Oncol. 2017;35(3):365-373. doi:10.1002/ hon. 2289

29. Galati D, Di Noto R, Del Vecchio L. Diagnostic strategies to investigate cerebrospinal fluid involvement in hematological malignancies. Leuk Res. 2013;37(3):231-237. doi:10.1016/j.leukres.2012.11.016

30. Reiber H. Dynamics of brain-derived proteins in cerebrospinal fluid. Clin Chim Acta. 2001;310(2):173-186. doi:10.1016/s0009-8981(01) 00573-3

31. Wakim JJ, Levenson BM, Mathews D, Naina HV. Management of an unusual case of intravascular large B-cell lymphoma of the penis, prostate, and bones with CNS relapse. J Clin Oncol. 2013;31(17): e288-290. doi:10.1200/JCO.2012.46.6003

32. Sawada T, Omuro Y, Kobayashi T, et al. Long-term complete remission in a patient with intravascular large B-cell lymphoma with central nervous system involvement. Onco Targets Ther. 2014; 7:2133-2136. doi:10.2147/OTT.S72596

33. Hegde U, Filie A, Little RF, et al. High incidence of occult leptomeningeal disease detected by flow cytometry in newly diagnosed aggressive B-cell lymphomas at risk for central nervous system involvement: the role of flow cytometry versus cytology. Blood. 2005;105(2):496-502. doi:10.1182/blood-2004-05-1982

34. Nizamutdinov D, Patel NP, Huang JH, Fonkem E. Intravascular Lymphoma in the CNS: options for Treatment. Curr Treat Options Neurol. 2017;19(10):35. doi:10.1007/s11940-017-0471-4

35. Pranzatelli MR, Tate ED, McGee NR, et al. Key role of CXCL13/CXCR5 axis for cerebrospinal fluid B cell recruitment in pediatric OMS. $J$ Neuroimmunol. 2012;243(1-2):81-88. doi:10.1016/j.jneuroim.2011.12. 014

36. Thal SC, Luh C, Schaible EV, et al. Volatile anesthetics influence blood-brain barrier integrity by modulation of tight junction protein expression in traumatic brain injury. PLoS One. 2012;7(12):e50752. doi:10.1371/journal.pone.0050752

37. Martin TA, Mansel RE, Jiang WG. Antagonistic effect of NK4 on HGF/SF induced changes in the transendothelial resistance (TER) and paracellular permeability of human vascular endothelial cells. $J$ Cell Physiol. 2002;192(3):268-275. doi:10.1002/jcp.10133

38. Muldoon LL, Lewin SJ, Dosa E, et al. Imaging and therapy with rituximab anti-CD20 immunotherapy in an animal model of central nervous system lymphoma. Clin Cancer Res. 2011;17(8):2207-2215. doi:10.1158/1078-0432.CCR-10-2923

39. Jahnke K, Hummel M, Korfel A, et al. Detection of subclinical systemic disease in primary CNS lymphoma by polymerase chain reaction of the rearranged immunoglobulin heavy-chain genes. J Clin Oncol. 2006;24(29):4754-4757. doi:10.1200/JCO.2006.06.7165
40. Soto MS, Serres S, Anthony DC, Sibson NR. Functional role of endothelial adhesion molecules in the early stages of brain metastasis. Neuro Oncol. 2014;16(4):540-551. doi:10.1093/neuonc/not222

41. Harhaj NS, Antonetti DA. Regulation of tight junctions and loss of barrier function in pathophysiology. Int J Biochem Cell Biol. 2004;36 (7):1206-1237. doi:10.1016/j.biocel.2003.08.007

42. Argaw AT, Gurfein BT, Zhang Y, Zameer A, John GR. VEGFmediated disruption of endothelial CLN-5 promotes blood-brain barrier breakdown. Proc Natl Acad Sci U S A. 2009;106(6):1977-1982. doi:10.1073/pnas.0808698106

43. Ram M, Sherer Y, Shoenfeld Y. Matrix metalloproteinase-9 and autoimmune diseases. J Clin Immunol. 2006;26(4):299-307. doi:10. 1007/s10875-006-9022-6

44. Grossetete M, Phelps J, Arko L, Yonas H, Rosenberg GA. Elevation of matrix metalloproteinases 3 and 9 in cerebrospinal fluid and blood in patients with severe traumatic brain injury. Neurosurgery. 2009;65 (4):702-708. doi:10.1227/01.NEU.0000351768.11363.48

45. Lemma SA, Pasanen AK, Haapasaari K-M, et al. Similar chemokine receptor profiles in lymphomas with central nervous system involvement - possible biomarkers for patient selection for central nervous system prophylaxis, a retrospective study. Eur J Haematol. 2016;96 (5):492-501. doi:10.1111/ejh.12626

46. Gerard C, Rollins BJ. Chemokines and disease. Nat Immunol. 2001;2 (2):108-115. doi:10.1038/84209

47. Biber K, Vinet J, Boddeke HW. Neuron-microglia signaling: chemokines as versatile messengers. J Neuroimmunol. 2008;198(1-2):6974. doi:10.1016/j.jneuroim.2008.04.012

48. Mastroianni CM, Lancella L, Mengoni F, et al. Chemokine profiles in the cerebrospinal fluid (CSF) during the course of pyogenic and tuberculous meningitis. Clin Exp Immunol. 1998;114(2):210-214. doi:10.1046/j.1365-2249.1998.00698.x

49. Eugenin EA, Osiecki K, Lopez L, Goldstein H, Calderon TM, Berman JW. CCL2/monocyte chemoattractant protein-1 mediates enhanced transmigration of human immunodeficiency virus (HIV)infected leukocytes across the blood-brain barrier: a potential mechanism of HIV-CNS invasion and NeuroAIDS. $J$ Neurosci. 2006;26(4):1098-1106. doi:10.1523/JNEUROSCI.3863-05.2006

50. Basu SK, Remick SC, Monga M, Gibson LF. Breaking and entering into the CNS: clues from solid tumor and nonmalignant models with relevance to hematopoietic malignancies. Clin Exp Metastasis. 2014;31(2):257-267. doi:10.1007/s10585-013-9623-4

51. Christiansen I, Sundström C, Kälkner KM, Bring J, Tötterman TH. Serum levels of soluble vascular cell adhesion molecule-1 (sVCAM1) are elevated in advanced stages of non-Hodgkin's lymphomas. Eur J Haematol. 1999;62(3):202-209. doi:10.1111/j.1600-0609.1999.tb0 1746.x

52. Wen PY. Message from the Editor-in-Chief. Neuro-Oncology. 2017;19(1):1. doi:10.1093/neuonc/now279

53. Lin T-K, Yeh T-H, Hsu P-W, et al. Primary central nervous system lymphomas of the brain: a retrospective analysis in a single institution. World Neurosurg. 2017;103:550-556. doi:10.1016/j.wneu.2017. 03.095
OncoTargets and Therapy

\section{Publish your work in this journal}

OncoTargets and Therapy is an international, peer-reviewed, open access journal focusing on the pathological basis of all cancers, potential targets for therapy and treatment protocols employed to improve the management of cancer patients. The journal also focuses on the impact of management programs and new therapeutic agents and protocols on patient perspectives such as quality of life, adherence and satisfaction. The manuscript management system is completely online and includes a very quick and fair peer-review system, which is all easy to use. Visit http://www.dovepress.com/ testimonials.php to read real quotes from published authors. 